\title{
Effect of Blast Induced Ground Vibrations on Green Concrete at Mumbai Metro Rail Project
}

\author{
${ }^{* 1}$ Manoj Gurharikar, ${ }^{2}$ Manish Uttarwar, ${ }^{3}$ More Ramulu, ${ }^{4}$ Pradeep Gujjula \\ 1,2 Rajiv Gandhi College of Engineering, Research \& Technology, Chandrapur \\ ${ }^{3,4}$ CSIR-Central Institute of Mining \& Fuel Research Nagpur Research Centre (MT), India \\ Email:manoj@rocktec.co.in,udmanish1@rediffmail.com,more.ramulu@gmail.com, \\ radeepgujjula2419@gmail.com
}

Received: 22nd October 2019, Accepted: 31st January 2020, Published: 29th February 2020

\begin{abstract}
In mining, civil construction projects drilling and blasting method widely used for rock excavation. Due to rock blasting many problems may occur such as flyrock, vibrations and etc. In fact 38-40 \% explosive energy utilising to produce vibrations only. [2] These blast induced ground vibration may cause damage newly performed bed concreting layers in construction process. There also arise similar problems in mining, where concrete supporting is required in drivages of weak rock. Therefore, investigation of on Effect of Blast Induced Ground Vibrations on Green Concrete and determining reasonable time gap and distance between blasting work and concreting is of great importance.

This paper presented review on effect of Vibrations on green concrete. The recommendations given by various researchers are broad and general in nature. This research attempted to correlate the strength acquired by the concrete with the threshold maximum vibration level. In this research, experimental blasts carried out during base slab concrete works of a Metro construction works in Mumbai. Peak Particle Velocity (PPV) recorded by using seismographs. Effect of PPV on green concrete strength with respect to time. This paper presented difference in strength of green concreate, which is exposed to blast vibrations with strength of green concrete without exposing vibrations with respect to age of green concreate.
\end{abstract}

\section{Keywords}

Green Concentrate, Young Shotcrete, Blasting, Vibration, Peak Particle Velocity (PPV)

\section{Introduction}

Explosive are being used as primary source of energy for rock and concrete breakage in most of the mining and civil engineering applications. The effective utilisation of explosive energy has been reported to be around 15 per cent. [2] Major part of explosive energy, which is not used for rock fragmentation, results in generating undesirable side effects like ground vibrations, air overpressure and flyrock. The vibration energy that travels beyond the zone of rock breakage is wastage and results in structural damage and human annoyance. In a properly designed and executed production blast, in general, only $20-25 \%$ of the total explosive energy is utilised in useful work, and remaining $75-80 \%$ of energy is being wasted in generation of ill effects.[10]

Ground vibration is an elastic deformation of ground due to blast-induced forces and air overpressure is a transient increase in air pressure (above or below the atmospheric pressure) arising from the detonation of an explosive. The unproductive explosive energy used for generation of vibrations and air overpressure can travel many kilometres under favourable geological conditions and cause disturbance to the structures and habitats in the vicinity. Surface blasting in general, results in both positive and negative effects with regards to the safety and productivity (Fig 1). Since blasting is the cheapest method of rock breakage, mining and civil construction projects, in general, adopt the method for rock breakage and excavation. Even small scale blasts near structures and vital installations may generate dangerous vibration levels. Now-a-days prediction of blast induced ground vibrations is becoming increasingly important because of the fact that mining activity is spreading towards populated areas as well as the urban sprawl near mines and quarries. Therefore fine-tuning of the causative and control parameters of the vibrations and air overpressure has become a thrust area of investigation in the present day context.

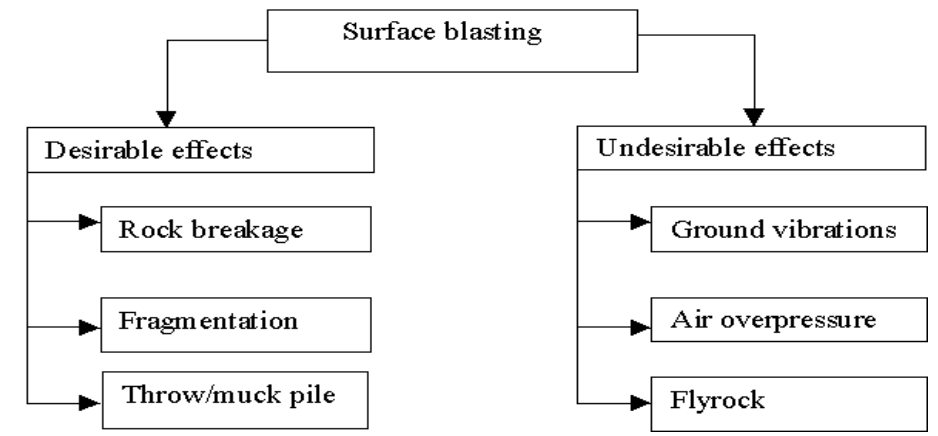

Fig 1: Desirable and Undesirable Effects of Surface Blasting 


\section{Review on Effect of Vibrations on Green Concrete}

Hulshizer and Desai (1984) [3] use the term "green concrete"' to describe conventional concrete having an age of less than 24 hour after completion of placement. Byfors (1980) [1] defines "fresh concrete", as concrete before setting, "early age concrete" as concrete between setting and approximately 1-3 days of age, "almost hardened concrete" as concrete older than 1-3 days, but younger than 28 days which defines a "hardened concrete"'. In the following, "young shotcrete", will be used for shotcrete up to one day old.

The effect of vibrations on green concrete has not been fully investigated by researchers in the past. Except few researchers [6], no published material on the effect of vibrations on young shotcrete has been found. There are, however, a number of interesting reports on in-situ tests conducted in tunnels and mines where fully cured shotcrete on rock have been subjected to blast induced vibrations. Some research attempts were made in the area of influence of vibrations on young shotcreting, which is similar to the effect of green concrete. [8]

Kendorski et al. (1973) [5] carried out in-situ tests to determine how a concrete lining was affected by standard drift blasts at various distances from the lining. A standard blast that consisted of $409 \mathrm{~kg}$ premixed ammonium and fuel oil (ANFO) showed that there was no bond failure at the shotcrete-rock interface. The tests revealed that cracks started to appear in the shotcrete when the detonations occurred at a distance of $16.5 \mathrm{~m}$ and that the function of the lining was considerably reduced when detonating from $12.2 \mathrm{~m}$.

In civil construction projects, the strive for a more time-efficient construction process naturally focuses on the possibilities of reducing the time periods of waiting between stages of construction. As an example, the rock excavation in open cut excavations in metro rail projects requires coordination between the bed concreting and adjacent rock blasting so that blast induced vibrations would not affect the green concrete which is hardly at a distance of 5-10m.[8] There also arise similar problems in mining. To be able to excavate as much ore volume as possible, the grid of drifts in a modern mine is dense. This means that supporting systems in one drift are likely to be affected by vibrations in a neighbouring drift. A criterion for how close, in time and distance, to the young concrete, blasting can take place would be an important tool in planning for safe and economical mining projects. Another example is the foundation excavation of thermal power projects, where the concreting and rock excavation go simultaneously, adjacent to each other, to crash the time.

In actual practice, numerous occasions arise when it is necessary to build concrete structures at the same time when excavations by blasting are being carried out. For example, lining during tunnel driving, foundation for the primary crushing buildings near open pits, etc. Table-1 gives prevention criteria given by Oriard (1980) [6] depending upon curing or hardening time of the concretes, although such recommendations cannot be made extensive to all types of concrete.

As can be observed, during the hardening period of 0 to 4 hours, the concrete is still not hard and the admissible levels are relatively high. From 4 to 24 hours, it begins to harden slowly, and after 7 days it reaches the strength that is approximately $2 / 3$ of the final product ( 28 days), allowing a progressive intensification of the vibrations. Other factors to take into account are the characteristic frequencies of the vibrations, external hardening conditions, area of rock-concrete contact, etc. On the other hand, Issac \& Bubb (1981),[4] summed up all their experiences and those of Scandinavian investigators in a graph where, according to strength acquired by the concrete, the maximum vibration level is determined.

\begin{tabular}{|l|l|l|}
\hline \multicolumn{1}{|c|}{ Setting Time } & Admissible level of PPV \\
\hline & STRUCTURAL CONCRETE & FILL AND MASS CONCRETE \\
\hline $0-4 \mathrm{hrs}$ & $50 \mathrm{~mm} / \mathrm{s}$ & $100 \mathrm{~mm} / \mathrm{s}$ \\
\hline $4-24 \mathrm{hrs}$ (1-3 days) & $5 \mathrm{~mm} / \mathrm{s}$ & $25 \mathrm{~mm} / \mathrm{s}$ \\
\hline $24-72 \mathrm{hrs}$ (3-7 days) & $25 \mathrm{~mm} / \mathrm{s}$ & $30 \mathrm{~mm} / \mathrm{s}$ \\
\hline $72-168 \mathrm{hrs}$ (7-10 days) & $50 \mathrm{~mm} / \mathrm{s}$ & $75 \mathrm{~mm} / \mathrm{s}$ \\
\hline $168-240 \mathrm{hrs}$ days) & $125 \mathrm{~mm} / \mathrm{s}$ & $200 \mathrm{~mm} / \mathrm{s}$ \\
\hline$>240 \mathrm{hrs}(10$ da & $250 \mathrm{~mm} / \mathrm{s}$ & $375 \mathrm{~mm} / \mathrm{s}$ \\
\hline
\end{tabular}

Table 1: Setting Time of Concrete versus Admissible Levels of Particle Velocities

\section{Methodology}

The guidelines given by the previous research findings are broad and general in nature. Therefore, it requires further experimentation to correlate the strength acquired by the concrete with the threshold maximum vibration level. Therefore, it is very essential to know the exact effect of vibrations on green concrete to avoid possible damage and deterioration to the structure in long run.

\section{Field Experimentation}

Blasting of hard rock was carried out as part of the excavation works in connection with proposed underground stations for Mumbai Metro Rail Corporation Limited(MMRCL), at different locations at the MMRCL station in Mumbai city, India. Controlled blasting operations were carried out keeping in view of the adverse effects like ground vibration and air overpressure and flyrock. Blasting and concrete works used to go hand in hand to meet the time schedules and targets of the project. Therefore, freshly poured concrete was exposed to blast induced ground 
vibrations as shown in Fig 2. In such situations it was imperative to know the exact levels of ground vibrations, which cannot cause any internal and external damage to the green concrete.

The following sets of experiments carried out for assessing the effect of blast induced ground vibrations on green concrete:

1. Close field ground vibration monitoring at freshly poured concrete by triaxial geophones

2. Measurement of curing characteristics like strength and temperature release of freshly poured concrete/green concrete by a device called Zone-cure at vibration free zone.

3. Measurement of curing characteristics like strength and temperature release of freshly poured concrete/green concrete at vibration exposed zone.

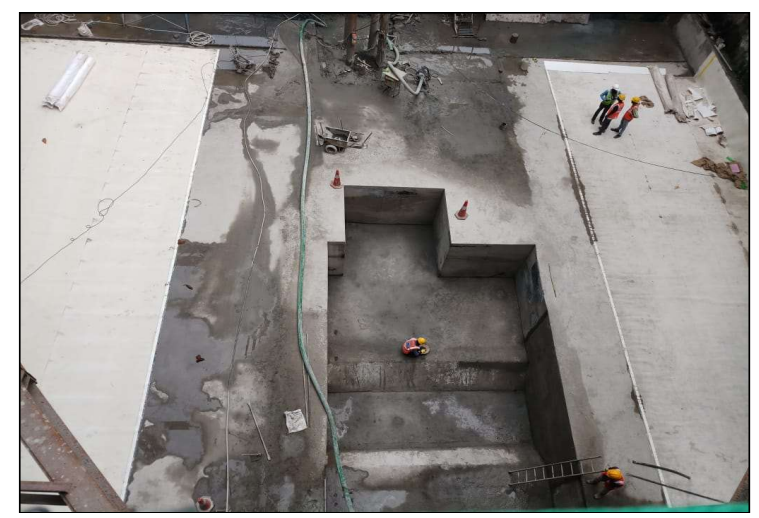

Fig 2: Freshly Poured Concrete near Blasting Sites at Mumbai Metro Rail Project

Some experiments were carried out during base slab concrete works of a Metro construction works in India to find out the vibration criteria for freshly poured concrete of age 0 to 4 hours. From the temperature history graphs it was found that the temperature of concrete starts increasing after 2 hours, which is the indication of curing process. At the experimental site the structural concrete was exposed to a blast induced vibration with peak particle velocity (PPV) level of $46 \mathrm{~mm} / \mathrm{s}$, which was still less that the threshold limit suggested by Oriard (1980).[6] The vibration monitoring was carried out by engineering seismograph of Instantel make (Canada), which contains triaxial geophones as shown in Figure 3. The vibration level was exposed at 3 hour 15 minutes from concreting. The vibration exposure took place in twice with a gap of 5 minute. There was another site with same structural concrete kept without any exposure of vibrations. After 15 days of curing, samples of both the sites were tested for strength. The in-situ strength was tested by a Concrete Maturity Testing Systems called Zone Cure. Very interestingly the strength of vibration free concrete sample measured was $40.7 \mathrm{MPa}$ and that of vibration exposed samples was 31.8 $\mathrm{MPa}$. This indicates the vibration exposure resulted in strength reduction of $22 \%$, which is very substantial one.

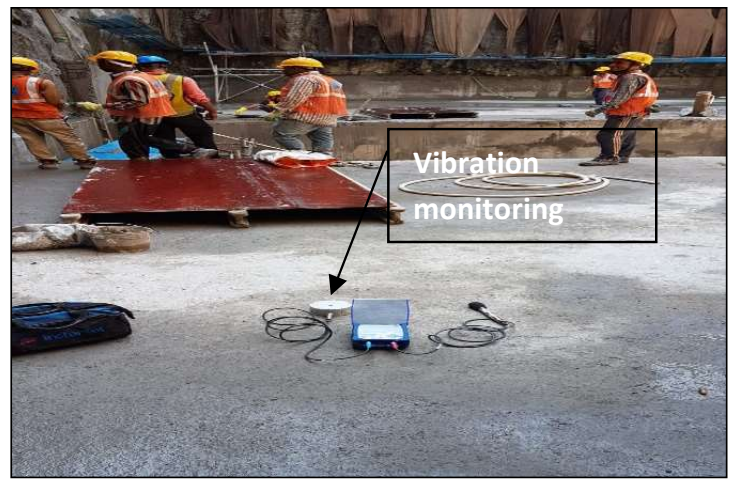

Fig 3: Vibration Monitoring by Engineering Seismograph near the Green Concrete

Similar experiments were conducted on samples of 3 hours age and with exposure of PPV $47.8 \mathrm{~mm} / \mathrm{s}$ and observed $23.5 \%$ reduction in strength. This indicates that no chance of exposure of vibrations should be taken for the freshly poured concrete of age 2 to 4 hour, although the existing global vibration criteria is liberal for concrete up to 4 hour age. Therefore, the paper recommends that the green concrete up to 4 hour age is also vulnerable for vibrations above $40 \mathrm{~mm} / \mathrm{s}$ and stresses for need of more research and experiments in this direction.

\section{Results and Discussion}

Both strength and temperatures were monitored by fixing concrete curing measurement system Zone-cure at the site. The strength was measured for every 12 hours for a period of 15 days and temperature was measured for every 2 hours for a period of 24 hour. The experiment of strength and temperatures was carried out for a green concrete, which was exposed to a vibration level of $46-47.8 \mathrm{~mm} / \mathrm{s}$. The same experiment was carried out for a green concrete, 
which was not exposed to any vibration level. The experimental results of strength and temperatures are given in Table 2 and 3 respectively. The temperature monitoring indicate that curing process i.e. cement bonding starts between 2 to 4 hours as the raise in temperature is evident. The fall in strength after 15 days to the vibration exposed concrete indicate that there is substantial influence of vibration even at the levels at of $46-48.5 \mathrm{~mm} / \mathrm{s}$.

\begin{tabular}{|c|c|c|c|}
\hline SI No. & No. of hours & $\begin{array}{l}\text { Strength of green concrete } \\
\text { without exposing vibrations }\end{array}$ & $\begin{array}{l}\text { Strength of green concrete with exposing } \\
\text { vibrations (46-47.8mm/s) }\end{array}$ \\
\hline $\mathbf{1}$ & 12 & 7.6 & 4.4 \\
\hline $\mathbf{2}$ & 24 & 15.6 & 11.3 \\
\hline $\mathbf{3}$ & 36 & 20.1 & 14.77 \\
\hline $\mathbf{4}$ & 48 & 25.2 & 19.52 \\
\hline $\mathbf{5}$ & 60 & 27.5 & 21.80 \\
\hline $\mathbf{6}$ & 72 & 30.3 & 24.25 \\
\hline $\mathbf{7}$ & 84 & 32.5 & 27.28 \\
\hline $\mathbf{8}$ & 96 & 35.5 & 28.62 \\
\hline $\mathbf{9}$ & 108 & 36.7 & 29.35 \\
\hline $\mathbf{1 0}$ & 120 & 36.9 & 30.8 \\
\hline $\mathbf{1 1}$ & 132 & 37.9 & 30.64 \\
\hline $\mathbf{1 2}$ & 144 & 38.55 & 30.25 \\
\hline $\mathbf{1 3}$ & 156 & 38.85 & 31.75 \\
\hline $\mathbf{1 4}$ & 168 & 39.5 & 31.87 \\
\hline $\mathbf{1 5}$ & 360 & 40.7 & 31.8 \\
\hline
\end{tabular}

Table 2: Experimental Results of Strength versus Time in Green Concrete

\begin{tabular}{|c|c|c|c|}
\hline SI No. & No. of hours & $\begin{array}{l}\text { Strength of green concrete } \\
\text { without exposing vibrations }\end{array}$ & $\begin{array}{l}\text { Strength of green concrete with exposing } \\
\text { vibrations (46-48.5mm/s) }\end{array}$ \\
\hline $\mathbf{1}$ & 0 & 28 & 28 \\
\hline $\mathbf{2}$ & 2 & 25 & 25 \\
\hline $\mathbf{3}$ & 4 & 27 & 26 \\
\hline $\mathbf{4}$ & 6 & 32 & 29 \\
\hline $\mathbf{5}$ & 8 & 40 & 37 \\
\hline $\mathbf{6}$ & 10 & 51 & 45 \\
\hline $\mathbf{7}$ & 12 & 58 & 50 \\
\hline $\mathbf{8}$ & 14 & 55 & 48 \\
\hline $\mathbf{9}$ & 16 & 50 & 45 \\
\hline $\mathbf{1 0}$ & 18 & 47 & 42 \\
\hline $\mathbf{1 1}$ & 20 & 45 & 40 \\
\hline $\mathbf{1 2}$ & 22 & 40 & 39 \\
\hline $\mathbf{1 3}$ & 24 & 36 & 35 \\
\hline
\end{tabular}

Table 3: Experimental Results of Temperature versus Time in Green Concrete

\section{Conclusions}

In this work, blasting vibration parameter peak particle velocity (PPV) monitoring was during the blast excavation of Mumbai metro construction works. The effect of vibration on freshly poured concrete of age 0 to 4 hours investigated. The reasonable time gap between blasting and shotcrete proposed to ensure the security of shotcrete. The main conclusions were drawn as follows:

1. The strength of green concrete samples which is not exposed to blast vibrations was $40.7 \mathrm{MPa}$ and that of vibration exposed samples was $31.8 \mathrm{MPa}$. This indicates the vibration exposure resulted in strength reduction of $22 \%$

2. The samples of 3 hours age and with exposure of PPV $48.5 \mathrm{~mm} / \mathrm{s}$ and observed $23.5 \%$ reduction in strength. This indicates that no chance of exposure of vibrations should be taken for the freshly poured concrete of age 2 to 4 hour, although the existing global vibration criteria is liberal for concrete up to 4 hour age.

Therefore, the paper recommends that the green concrete up to 4 hour age is also vulnerable for vibrations above $40 \mathrm{~mm} / \mathrm{s}$ and stresses for need of more research and experiments in this direction. The lower time limit of $0-4 \mathrm{hrs}$ should be kept of $0-3$ hrs hours as the cement starts curing after three hours and the vibration threshold of $50 \mathrm{~mm} / \mathrm{s}$ should be changed as 40 for structural concrete for the first 3 hours exposure to ground vibrations.

\section{Acknowledgement}

The authors thankfully acknowledge the cooperation extended by Mumbai Metro Rail Corporation during the field studies. The authors also express their thanks to Director, CSIR-CIMFR for his cooperation and encouragement for 
this study and for permitting to publish this paper. The views expressed in the paper are those of the authors and not necessarily of the organizations they represent.

\section{References}

1. Byfors, J., 1980. Plain concrete at early ages, Research Fo 3:80. Swedish Cement and Concrete Research Institute, Stockholm.p. 345.

2. Hagan, T. N. and Just, J. D., 1974, Rock breakage by explosives-theory optimisation, Proc. 3rd Cong. Rock Mech., 2, pp.1349-1358.

3. Hulshizer, A.J., Desai, A.J., 1984. Shock vibration effects on freshly placed concrete. J. Constr. Eng. Manage. $110,266-285$

4. Issac, I.D., and Bubb, C., (1981), “Geology at Dinorwic,” Tunnels and Tunnelling, British Tunnelling Sot., Vol. 11, No. 3, pp. 20-25.

5. Kendorski, F.S., Jude, C.V., Duncan, W.M., 1973. Effect of blasting on shotcrete drift linings. Min. Eng. 25, 384.

6. Oriard, L. L. and Coulson, J. H., 1980, "TVA Blast Vibration Criteria For Mass Concrete", Proc. Conf. of ASCE, Portland, OR, Preprint 80-175.

7. Ramulu, M. \& Raina, A.K., P.B. Choudhury, Sinha, A., 2010, Special tunnel blasting techniques- CIMFR contributions, November, 2010, Workshop on Tunnelling Quo Vadis? Kolkata.pp. 1-18.Books \& Journals Private Ltd.,

8. Ramulu, M., 2013, Controlled blast design, review and monitoring of ground vibrations, air overpressure and flyrock at BMRC project, Phase1, UG1, Bangalore, CIMFR Report.

9. Ramulu, M., Sitharam, T.G, 2010, Blast induced damage due to repeated vibrations in jointed gneiss rock formation, Int. Journal of Geotechnical Earthquake Engineering, IGI publications, USA, Vol. No.5, Sept. pp.31-39. 10. Rollins, 1980, Energy partitioning, Rock mechanics and explosive research center, University of Missori-Rolla 